\title{
Scientific Advances and Pharmacological Applications of Marine Derived-Collagen and Chitosan
}

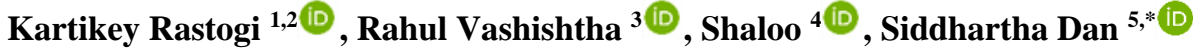 \\ 1 Indian Pharmacopoeia Commission, Uttar Pradesh, Ghaziabad 201002, India; kartikey.rastogi@ yahoo.com (K.R.); \\ 2 Department of Pharmacology, Shri Ram Murti Smarak Institute of Medical Sciences, Bareilly, Uttar Pradesh, 243202, \\ India; kartikey.rastogi@yahoo.com (K.R.); \\ 3 Department of Clinical Pharmacology \& Pharmacokinetics, Sun Pharm, Gurugram, Haryana 122003, India; \\ rahulvashistha14@gmail.com (R.V.); \\ 4 Department of Pharmacology, Council of Scientific and Industrial Research-Central Drug Research Institute, Lucknow, \\ Uttar Pradesh, 243202, India; shaloo373111@gmail.com (S.); \\ 5 Department of Biotechnology, I.K. Gujral Punjab Technical University, Jalandhar, Punjab 144603, India; \\ siddharthadan7@gmail.com (S.D.); \\ * Correspondence: siddharthadan7@gmail.com (S.D.);
}

Scopus Author ID: 57218994496

Received: 30.05.2021; Revised: 5.07.2021; Accepted: 10.07.2021; Published: 9.08.2021

\begin{abstract}
Collagen and chitosan and their combination are the most trending biomaterials at present due to their excellent bioavailability, biodegradability, biocompatibility, nontoxicity, and potent wound healing activity. Chitosan is obtained from chitin, a second-most freely accessible characteristic biomaterial after cellulose. Chitin is not soluble in weak acids, while chitosan dissolves in an acidic environment. Due to the dominance of primary amines $\left(-\mathrm{NH}_{2}\right)$ in the structure of chitosan, a net positive charge is gained by the molecule, which is significant for its pharmacological activity. Marine collagen is obtained from numerous marine sources like marine fishes, sponge, and mollusks. It plays a key job in tissue repair mechanism through its chemotactic properties, which attracts cells like fibroblasts and keratinocytes to the injury and gives the wound an alternative collagen source that is debased by elastase and matrix metalloproteinases (MMPs) as a conciliatory substrate. Many different types of chitosan and collagen have been pre-owned to an assortment of wound preparations, acting as a characteristic scaffold or substrate for new tissue development and making them the most favored biomaterial among wound experts. This review focuses on the key highlights of marine collagen and chitosan, their mechanism of action, pharmacological applications, and their use in biomedical engineering, particularly wound healing.
\end{abstract}

Keywords: biomaterials; marine collagen; chitosan; scaffold; tissue engineering; pharmacological applications.

(C) 2021 by the authors. This article is an open-access article distributed under the terms and conditions of the Creative Commons Attribution (CC BY) license (https://creativecommons.org/licenses/by/4.0/).

\section{Introduction}

In the course of recent decades, various research groups have been working on techniques to advance the wound healing process and the improvement of newer biomaterial utilizing chitosan and marine collagen. For many years, these two proteins are used in many experimental studies. In the animal kingdom, collagen is the only abundant protein with great pharmacological value. It has many applications that are carried out utilizing different sources, such as bovine, porcine, and birds. In spite of the fact that sources of collagen are plenteous, collagen from land creatures posed a threat to its usage in everyday life. Consequently, researchers searched for an alternative source and discovered marine collagen having potent 
tissue repair activity without potential side effects. It is composed of a long triple-helical structure (polyproline II-like helices) formed by three firmly joined peptidyl subunits composed of hydroxyproline, proline, and glycine (Figure 1), and the triple helix forms large fibrillar supermolecules at neutral $\mathrm{pH}[1]$.

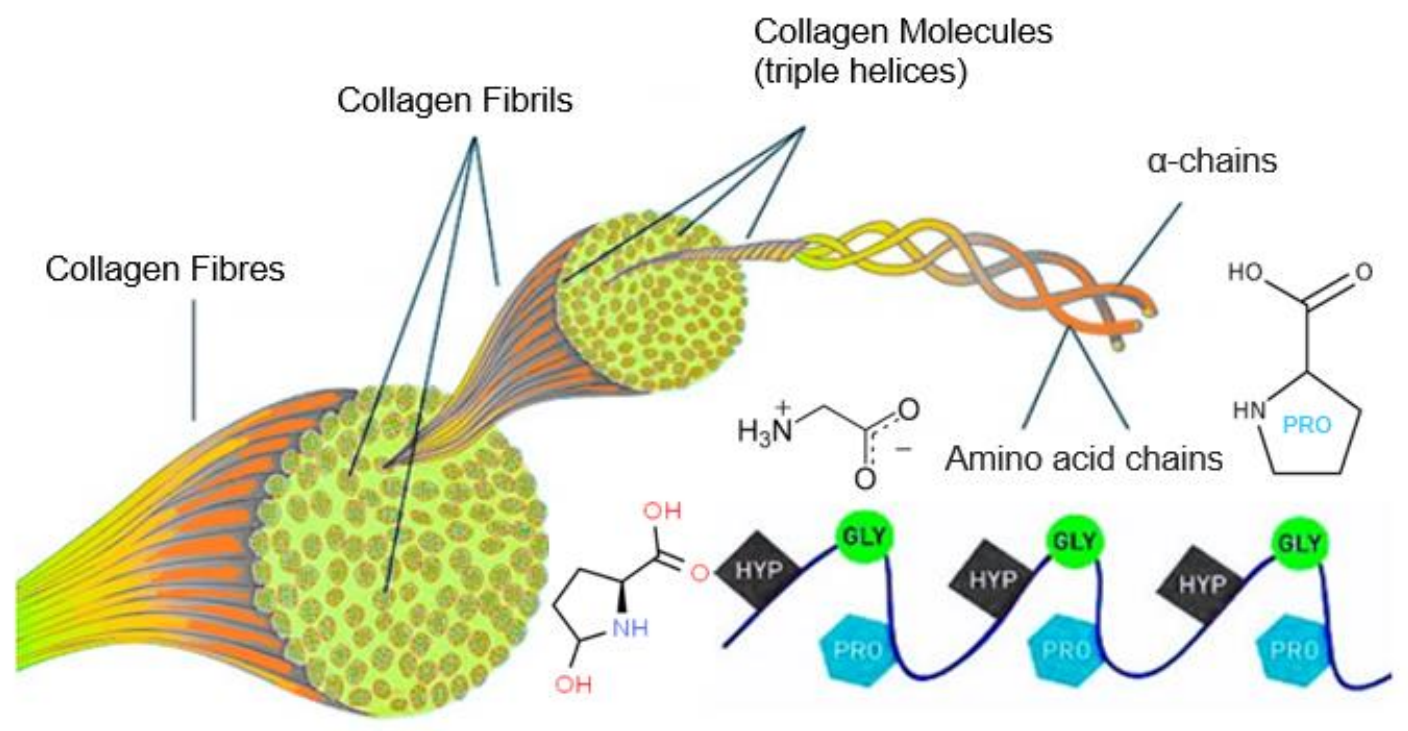

Figure 1. Triple helical structure of marine collagen protein.

It has additionally demonstrated tissue healing properties in numerous civil and battlefield applications. Fish collagen plays a crucial role in strengthening tissues by altering cellular functioning, including cell attachment and growth by interacting with other cellular proteins and their receptors. Chitosan has a natural origin, and it is composed of a linear polysaccharide chain obtained from enzymatic hydrolysis of chitin when deacetylated in a basic medium. In terms of its trading and marketing, it is the most sustainable biomaterial after cellulose [2]. Today, marine collagen and chitosan and their derivatives have gained significant attention in the biomedical field because of their exclusive biochemical properties. The most recognized properties of marine origin collagen and chitosan in the biomedical field are nontoxicity, environment-friendly, immunomodulatory, bacteriostatic, excellent bioavailability, and tissue repair activity. In vitro and in vivo studies have demonstrated their biodegradability where larger particles converted into monomer units [3]. The products procured by enzymatic degradation of chitin have shown no ADRs on living tissue. Chitosan has the ability to reduce cholesterol, inhibit bacterial growth by inhibition of mRNA. Both collagen and chitosan have been broadly utilized in numerous pharmacological applications. In wound healing as scaffolds or antibacterial dressings [4], in drug delivery as a carrier for distribution of drug at the site of the tumors, for gene delivery [5], in hemodialysis [6], and dentistry for absorbable sutures [7,8]. This article presents the most recent emerging pharmacological applications of chitosan and marine collagen-based biomaterials. This article also briefly explained chitosan and marine collagen, their characteristics, sources, synthesis, and utilization in different fields. 


\section{Sources and extraction of chitosan and marine collagen}

\subsection{Chitosan.}

The production of chitosan begins after selecting appropriate chitin sources either marine sources like crabs, prawns or non-animal sources like fungi indicated in (Table 1.) Based on the source, chitosan can have distinct physicochemical properties. There are two modes of chitin extraction and purification, i.e., demineralization and deproteination. To obtain chitosan, it is treated with strong bases, preferably sodium hydroxide. This procedure is known as deacetylation, and it also influences molecular weight, physiochemical properties of chitosan, such as the distribution of amine groups and net positive charge in the polymer. Byproducts of chitosan collaborate with living cells and tissues without causing any side effect in the human body. It interferes with the chain oxidation mechanism by displacing free radicals and acting as a bactericidal agent against many microorganisms. The antimicrobial property of chitosan essentially depends on the degree of deacetylation, molecular weight, $\mathrm{pH}$ value, presence of cation, $\mathrm{pKa}$, and microbial species from which chitosan is extracted [9]. The healing procedure of an injury involves a sequence of phases, namely hemostasis, inflammatory phase, migration \& proliferation phase, and remodeling phase. To provide better wound treatment to civilians, especially in the case of armed forces, research laboratories worldwide began to advance chitosan wound dressings, ensuring their safety and potency [10, 11]. Compared to many natural or chemically synthesized molecules, chitosan is accepted as a desirable biomaterial because of its important characteristics like polycationic nature that is active against many microbes including Gram-positive and Gram-negative bacteria, chelating and blocking agent inhibiting microbial growth.

Table 1. Sources of chitin/chitosan.

\begin{tabular}{l|l|l} 
Insects & Marine Animals & Microorganisms/Fungi \\
\hline Horned grass hoppers & Shrimps & Fungi cell wall \\
\hline Egg-Larva-Pupa-Adult & Lobsters & Brown algae \\
\hline Green bugs & Mollusks & Green algae \\
\hline Scorpions & Krill & Spores \\
\hline Brachiopods & Prawn & Mycelia penicillium \\
\hline Spiders & Crabs & Ascomydes \\
\hline Cockroaches & Coelenterata & Chytridiaceae \\
\hline Ants & Crustaceans & $\beta$-type yeast \\
\hline Beetles & Annelids & Blastocladiaceae
\end{tabular}

\subsection{Marine collagen.}

Marine origin collagen is the safest source for acquiring collagen in the present-day scenario. Another main purpose behind utilizing this compound is because of the fact that "life started from marine". Collagen that has been extracted from kingdom Animalia includes chicken, bovine, porcine, avian, rodent tail, ducks' feet, skin and ligaments of horses, sheep and alligators, toad skin, and sometimes even from humans is a complex, time tedious, and expensive process [12]. It had also reported encephalopathy and low bioavailability in certain instances. The output is also very low when contrasted with other sources. Because of these major concerns, such as antagonistic inflammation, autoimmune disorders, and the existence of different diseases among land creatures causing health complications, collagen from marine life has begun to be researched and investigated. Sources include the utilization of marine vertebrates and invertebrates, such as fishes, starfish, jellyfish, sponge, sea urchin, octopus, 
squid, cuttlefish, and sea anemone and prawns. Marine collagen protein is acquired by discarding a significant volume of fish weight (approximately 75\%) in the form of skin, bone, fins, head, gut, and scales. Among these deposits, a considerable amount of type I collagen is extracted out of having an economic value. However, if the source is fish cartilage, type II collagen is the preferred choice. Fishes that are on a healthy diet yield less amount of collagen than starved ones. Based upon the source of collagen, various methods have been suggested for acquiring collagen macromolecules that involve three major steps, i.e., preparation, extraction, and recovery. The entire process comprises separating fish and animal parts and then cleaning them with a suitable solvent. After that size has been reduced using mincing samples, a chemical pre-treatment is also given to remove the non-collagenous part. An acidic medium is generally utilized to solubilize collagen and designated as Acid Soluble Collagen (ASC) for the extraction phase. Yields of extracting collagen from various marine sources are reported in (Table 2). Enzymes like trypsin, pancreatin, ficin, bromelain, papain, or pepsin are most commonly utilized that aids in the solubilizing procedure. If treatment is done through pepsin, the subsequent extract is designated as Pepsin Soluble Collagen (PSC) [13]. This procedure is extremely helpful, as it cuts away peptide units precisely in the non-helical telopeptide domain of collagen, subsequently hydrolyzing few non-collagenous proteins, enhancing collagen concentration. It brings about a considerably purest form of collagen by solubilizing unwanted substances and reducing antigenicity instigated by telopeptide fragments. Marine origin collagen has supremacy over animal sources. It is characterized by high collagen content, high bioavailability, chemically inert, less antigenic, absorbed metabolically, biodegradable to normal body constituents, almost negligible toxicity such as TSE, BSE, foot and mouth disease, and minor regulatory issues $[14,15]$.

Table 2. Collagen extracted from various marine sources with percent yield.

\begin{tabular}{l|l|l} 
Sources & Source Tissue & Yield \\
\hline Bigeye snapper & Bone & ASC: $1.59 \%$ \\
\hline Largefin longbarbel catfish & Skin & ASC: $16.8 \% ;$ PSC: $28.0 \%$ \\
\hline Seaweed pipefish & Skin & ASC: $5.5 \%$ PSC: $33.2 \%$ \\
\hline Brown backed toadfish & Skin & PSC: $54.3 \%$ \\
\hline Ocellate pufferfish & Skin & ASC: $10.7 \% ;$ PSC: $44.7 \%$ \\
\hline Lizard fish & Scales & ASC: $0.79 \%$ \\
\hline Horse mackerel & Scales & ASC: $1.51 \%$ \\
\hline Grey mullet & Scales & ASC: $0.43 \%$ \\
\hline Flying fish & Scales & ASC: $0.72 \%$ \\
\hline Yellowback seabream & Scales & ASC: $0.90 \%$ \\
\hline Bigeye tuna & Bone & \\
\hline Squid & Skin & $53 \%$ \\
\hline Cuttlefish & Skin & ASC: $0.58 \% ;$ PSC: $16.23 \%$ \\
\hline Edible Jellyfish & Umbrella & $46.40 \%$ \\
\hline Brownbanded bamboo shark & Cartilage & ASC: $1.27 \% ;$ PSC: $9.59 \%$ \\
\hline Blacktip shark & Cartilage & ASC: $1.04 \% ;$ PSC: $10.30 \%$ \\
\hline Ribbon jellyfish & Umbrella & PSC: $9 \%-19 \%$ \\
\hline Marine Sponge & & $30 \%$ \\
\hline Yellowfin tuna & Swim bladder & $1.07 \%$ \\
\hline Bramaaustralis & Skin & $1.50 \%$ \\
\hline Sole fish & Skin & $1.93 \%$
\end{tabular}

\section{Mechanism of action of chitosan and collagen}

\subsection{Chitosan.}

The exact mechanism of chitosan for wound healing has not yet been discovered, but the information proposes three main approaches to control bleeding: 1. Plasma sorption, 2 . 
Erythrocytes coagulation and 3. Adhesion and activation of platelets as shown in (Figure 2A). Sorption of plasma has a key role in chitosan functioning as a hemostat. It has the ability to absorb 60-70 \% fluid from its initial weight that aids in the aggregation of RBCs and platelets at the wound site. The rate of sorption relies upon the chitosan source, degree of deacetylation, and molecular weight. However, sorption is not a fundamental aspect that can stop bleeding.

Coagulation of erythrocytes is legitimately connected with the hemostatic property. In the presence of chitosan, hemagglutination occurs due to crosslinking of erythrocyte cells. They are bonded together by a polymeric chain of chitosan and form a lattice that can hold cells forming a strong clot. In blood, the morphology of erythrocytes is altered when it comes in contact with chitosan. Their shape changes seemed to have an uncommon affinity towards each other. Jefferson Muniz de Lima et al. showed that the acidic $\mathrm{pH}$ of chitosan could cause hemolysis of human RBCs, but a balanced $\mathrm{pH}$ possesses higher hemagglutination index [16]. Chitosan can directly persuade erythrocyte adhesion without establishing any complex structures or adhesion of any plasma proteins. Additionally, it retains fibrinogen and other blood proteins that improve the adhesion of RBC and coagulation. Fan W. et al. explained that chitosan of low molecular weight could tie with erythrocyte wall carrying a positive charge, and this might be a principal mechanism of hemostasis [17]. Likewise, there is certain information that describes that chitosan is more effective than chitin. Based on Scanning Electron Microscope (SEM) assessment, platelets were firmly attached and bonded to each other, framing an irregular pattern over the surface of chitosan particles [18]. To sum up the hemostatic action of polycationic chitosan, it can be concluded that primary plasma sorption acts on blood cells at the injured site. The positive charge of $-\mathrm{NH}_{3}$ interacts with anions present at the erythrocyte surface, leading to RBC aggregation, causing quick clot formation without systemic hemostasis.

\subsection{Marine collagen.}

Researchers have identified collagen as the common biomaterial in wound healing for a long time, and it plays an important job in the body's natural healing response. When the skin is injured, collagen becomes the common denominator in the body's healing response. Collagen enables the body to heal itself by preparing the wound bed, adjusting wound chemistry, causing cell migration and development, prompting granulation tissue, and improving overall skin tone. Collagen's role in these various mechanical, chemical and biological components frames an environment helpful for wound healing, and finally, to wound closure. When the blood vessels are injured, collagen is exposed and attracts platelets from the blood, which causes blood clotting. Fibroblasts and keratinocytes are accumulated at the site of injury to support angiogenesis and re-epithelialization. Elastase activates MMPs that help degrade key ECM components such as elastin and collagen at the cellular level. MMPs also have a significant role in breaking unhealthy ECM components to form new tissues [19]. If the level of MMPs is elevated for a prolonged timeframe within a wound, this results in inflammation and delays wound healing due to the destruction of healthy ECM. If the normal physiological processes do not stabilize additional MMPs, other approaches are needed to reduce protease levels within the wound milieu. The primary substrate of the enzyme is the elastin protein of ECM responsible for dermal tissue elasticity. The action of elastase is high in chronic wounds. Elastase helps in the conversion of pro-MMPs into active MMPs. In doing as such, elastase subsidizes strongly to MMP load in a chronic wound. Elastase, being a nonspecific protease, can likewise tie to native collagen and ultimately degrade. 


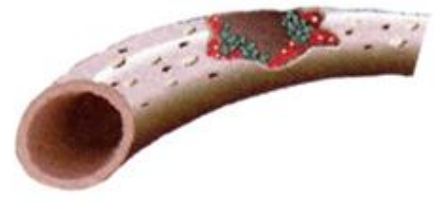

Polycationic chitosan binds to -ve charged erythrocyte that stimulate coagulation and activate platelets leading to haemostasis

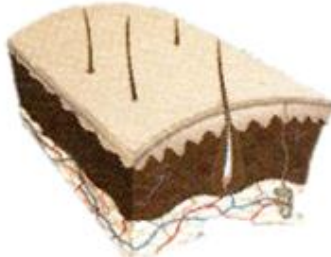

Wound remodeling regains A

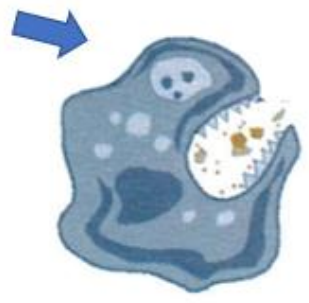

Wound debridement cleanses the wound

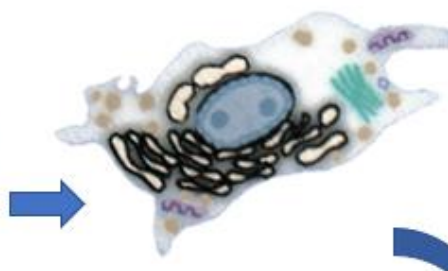

Fibroblastic activity creates structural matrix

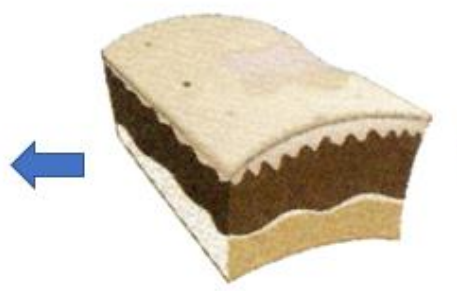

Re-epithelization closes the wound by binding fibronectin \& depositing organised fibres

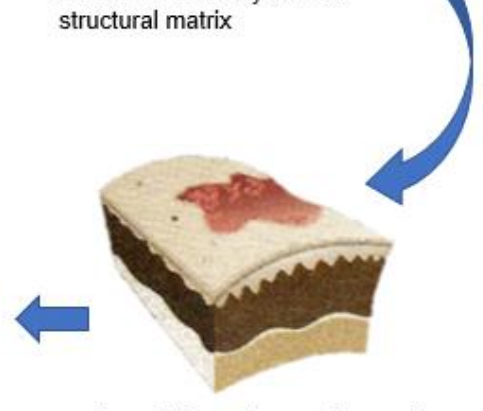

Granulation \& angiogenesis establishes new tissue \& blood vessels

\section{Role of MMPs and ELASTASE}

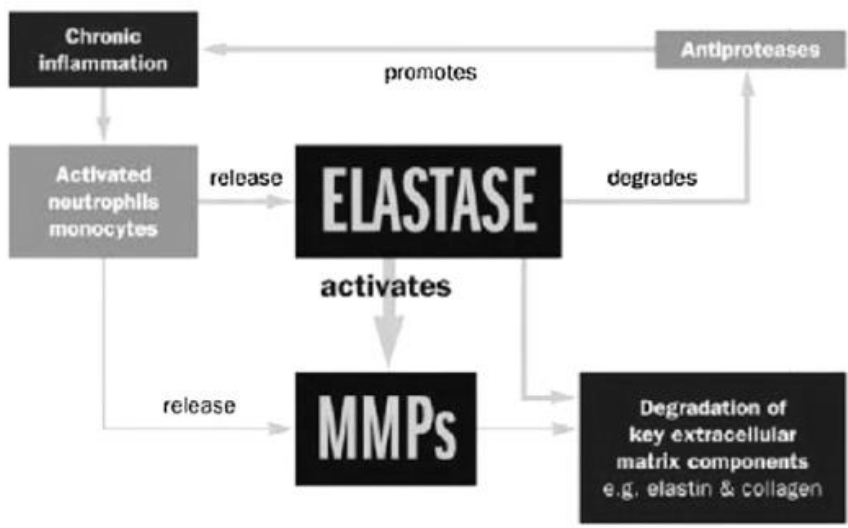

B

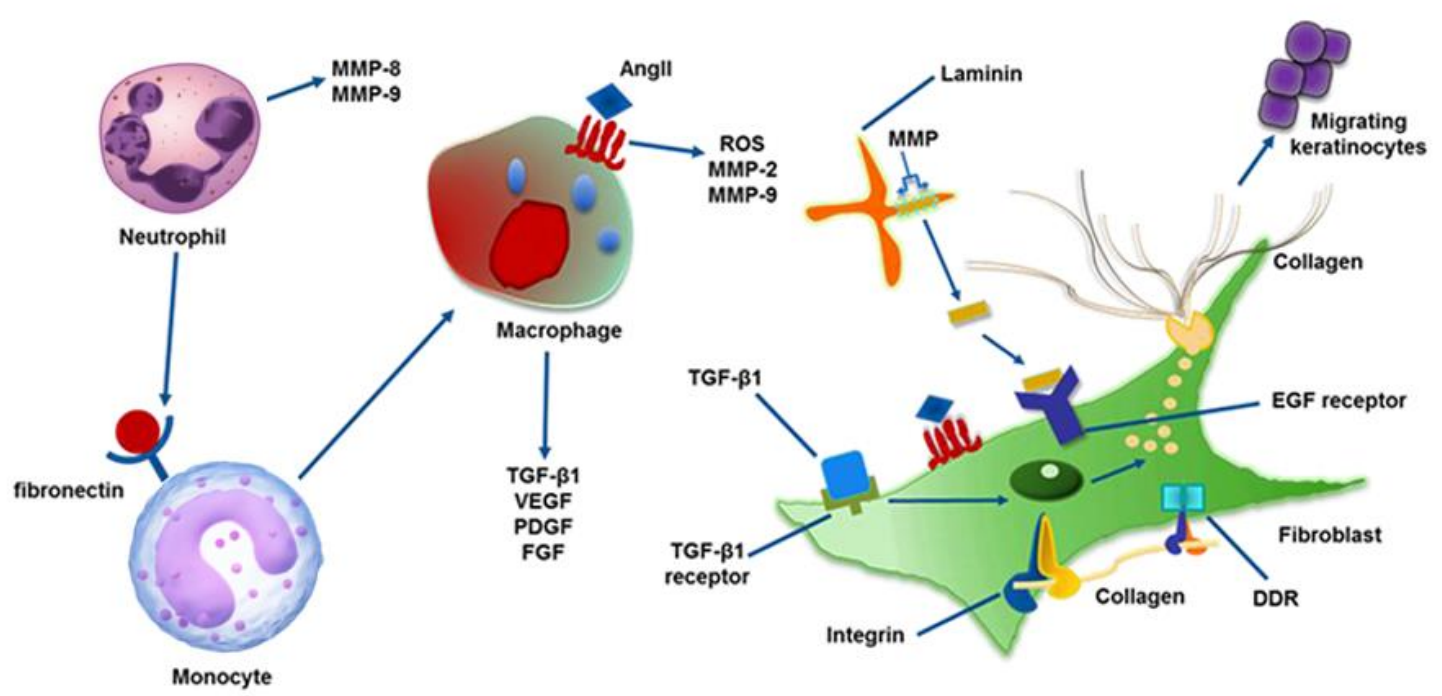

Figure 2. (A) Role of polycationic chitosan (B) MMPs and elastase in wound healing mechanism. MMPs: Matrix metalloproteinases; Ang II: Angiotensin II; ROS: Reactive oxygen species; TGF- $\beta 1$ : Transforming growth factor-beta1; VEGF: Vascular endothelial growth factor; PDGF: Platelet-derived growth factor; FGF:

Fibroblast growth factor; EGF: Epidermal growth factor; DDR: Discoidin domain receptor. 
When the dermis is injured, collagen peptides result in activation of MMPs and elastase enzyme. They act as substituted precursors for generating false signals, detected by fibroblasts for stimulating the synthesis of tropocollagen bundles and processing collagen neuropeptides (Figure 2B). After an injury, platelets at the wounded region start to accumulate around collagen and secrete clotting factors that stimulate the intrinsic clotting cascade, resulting in the formation of a stable hemostatic "plug". aa-granules are also secreted by platelet stimulating growth factors (GFs) and cytokines such as platelet-derived growth factor (PDGF), insulin-like growth factor 1 (IGF-1), epidermal growth factor (EGF), fibroblasts growth factor (FGF), and TGF- $\beta$. Inflammatory cells like neutrophils, eosinophils, and monocytes are also secreted at the wound site during the inflammatory phase to remove bacteria and cellular debris. Activated macrophages secrete TNF- $\alpha$ to produce interleukin-1 $\beta$. IL- $1 \beta$ is mitogenic for fibroblasts and controls the expression of MMP. Pro-inflammatory cytokines like TNF- $\alpha$ and IL-1 $\beta$ influences collagen deposition in wounds by promoting collagen synthesis via fibroblast cells, and it also down-regulates the level of TIMPs. Byproducts released due to collagen degradation stimulate the proliferation of fibroblasts that secrete growth factors such as KGF, bFGF, TGF- $\beta$, PDGF, and IGF-1KGF necessary for ECM growth.

To summarise, Marine collagen's role in wound healing starting from hemostasis with the binding of collagen to receptor sites on platelet membranes that swell and release constituents to initiate hemostasis. Collagen ties to glycoprotein fibronectin for adhesion and aggregation of platelets. Collagen is chemotactic to monocytes and leukocytes. Monocytes transform into macrophages which scavenge and phagocytize foreign bodies and debris for wound debridement. Granulation and angiogenesis begin when collagen binds with monocyte cells and convert them into macrophages. Macrophages engulf and destroy microbes from the wound surface. There is also the growth of new blood vessels, fibers, cells, capillaries, and ECM materials supported by collagen protein. Collagen binds with fibronectin, promoting fibrillogenesis, influencing fibril dimensions, and stimulating fibroblast proliferation and migration. It provides a substrate for directed migration and permeation of fibroblasts. It helps in the migration of keratinocytes and the organization of new tissue matrix to form new cells and tissues. Wound Remodeling is the last step during which collagen reduces scarring by depositing oriented and organized fibers and regulating the amount of collagenase expressed by keratinocytes. Normally, it takes around 21 days for complete wound healing.

\section{Pharmacological applications of chitosan and marine collagen}

Chitosan and marine collagen-based products have a number of pharmacological applications because of their inimitable physiochemical properties like biocompatibility, accessibility, characteristic antibacterial property, and biodegradability. Marine collagen has diverse clinical functions in managing complications of bones and skin, and it is the most widely used biomaterial in the development of pharmaceuticals. In tissue building, chitosan and marine collagen are reasonable molecules of interest for constructing ECM materials [20]. These biomaterials are utilized to prepare different kinds of wound dressing since they have prominent tissue healing potential, as discussed above. Chitosan is utilized as a carrier for drug delivery in the human body and different medicinal purposes. Some clinical approaches to chitosan include its utilization in kidney failure, tissue repair as a scaffold, ocular therapies, and hemodialysis [21]. Chitosan as a carrier, deliver active pharmaceutical ingredient and medications [22], in quality and malignancy treatment [23], bioimaging and dentistry acting as antibacterial agent [24]. Marine collagen is a drug delivery component, tissue engineering 
product, and pharmaceutical in diabetes, obesity, and skin aging. Some potential applications have been discussed in detail (Figure 3).

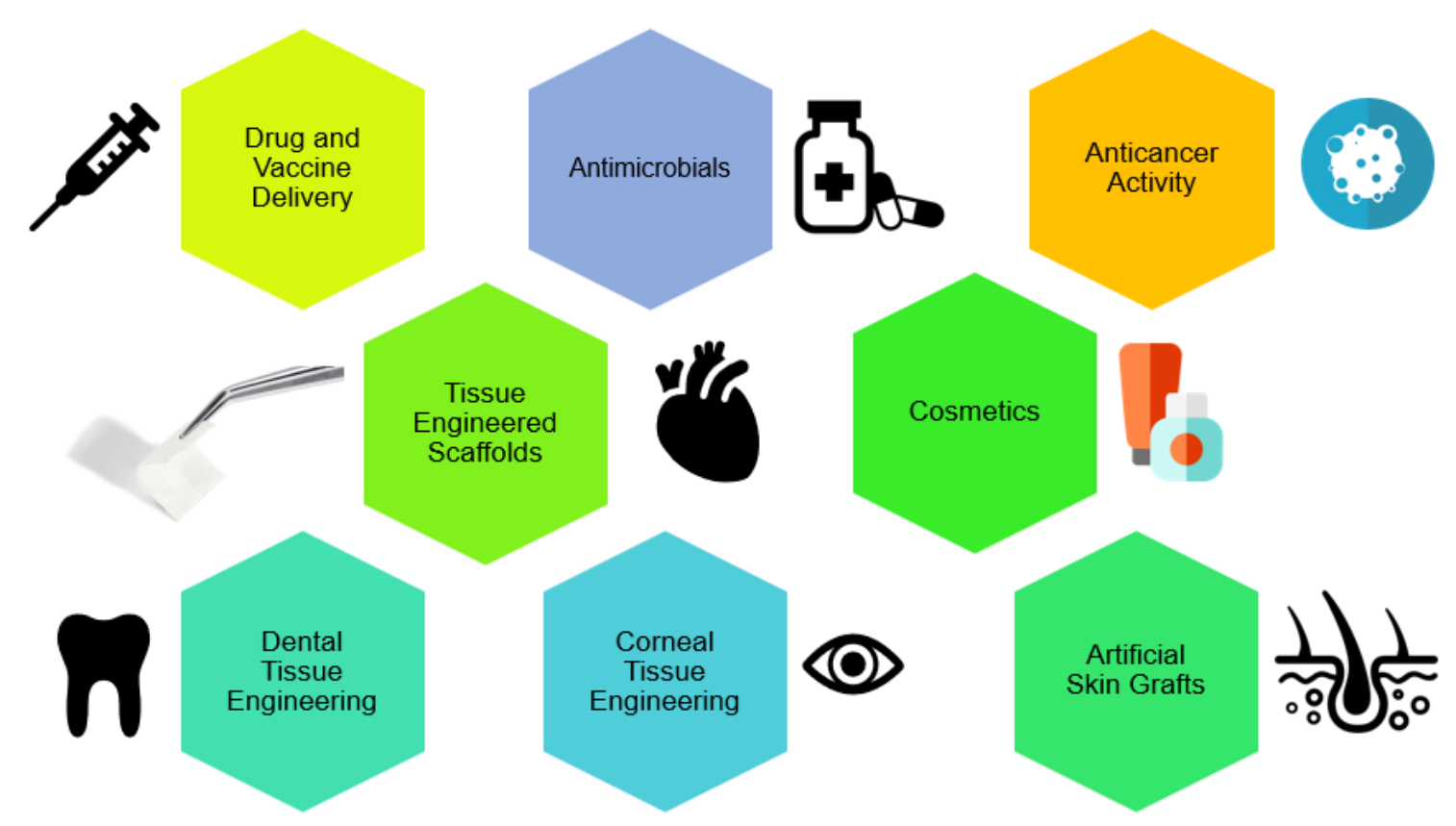

Figure 3. Potential pharmacological applications of chitosan and marine collagen.

\subsection{Role of chitosan in vaccine and drug delivery.}

Chitosan $(\mathrm{CH})$ has been tested for a number of drugs and vaccine delivery. In fact, various forms are developed and used in drug delivery applications as drug conjugate, nanofiber, absorbable scaffolds, microspheres, aerogels, and so on [25]. Anticancer drugs like cisplatin and glutaraldehyde, their derivatives when combined with $\mathrm{CH}$, they indicated excellent anticancer activity in the cancerous hepatic cells of dog. When examined, there was a significant reduction in the number of venues inside the liver. Necrosis and hepatic cell relapse in the immobilized locale were observed utilizing non-cholesterol- $\mathrm{CH}$ hydrogels. Polyelectrolytic compounds of $\mathrm{CH}$ with peptides were analyzed for drug release study. For instance, $\mathrm{CH}$-enhanced lipid-insulin complex and $\mathrm{CH}$-insulin conjugate are administered orally. $\mathrm{CH}$-gelatine microparticles with specified zeta potential are given through the nasal route. Transdermal insulin patches delivery is achieved through low molecular weight $\mathrm{CH}$ and alginate-chitosan-based microparticles. Calcitonin and Mannitol incorporated with $\mathrm{CH}$ have demonstrated satisfactory results. $\mathrm{CH}$-neomycin proved to be a safer drug choice for the treatment of the internal ear [26]. CH nanoparticles are being utilized for DNA vaccine carrier [27], nasal vaccine [28], injectable and mucosal delivery, and vaccine adjuvant chitosan promotes cellular immunity through interferons [29]. However, different antitoxins are administered with $\mathrm{CH}$ delivered both systemic and localized immune responses. Phase I clinical investigation of intranasal influenza vaccine developed with $\mathrm{CH}$-glutamate demonstrated favorable outcomes. It has been observed that anti-inflammatory drugs, when combined with $\mathrm{CH}$-microparticles, have a long-term effect, extended drug delivery (Table 3). Some examples of drugs that were combined with $\mathrm{CH}$ are betamethasone and indomethacin [30]. CH improves dextran sodium sulfate-induced ulcerative colitis by enhancing intestinal barrier functioning and regulating microflora in mice models [31]. $\mathrm{CH}$ hydrogel combined with bone morphogenetic protein (BMP-7) demonstrated the capacity to repair blemishes and scars. 
Moreover, chondroitin sulfate from ligament along with $\mathrm{CH}$ has shaped cartilaginous tissues [32]. Chitosan is not only used as a carrier protein but also in a large number of delivery systems. It possesses great affinity when combined with other drugs without causing any adverse reaction.

Table 3. Chitosan-based drug delivery systems.

\begin{tabular}{l|l|l|l|l}
$\begin{array}{l}\text { Antibiotic } \\
\text { systems }\end{array}$ & $\begin{array}{l}\text { Anticancer } \\
\text { systems }\end{array}$ & $\begin{array}{l}\text { Therapeutic } \\
\text { proteins/peptides }\end{array}$ & $\begin{array}{l}\text { Anti-inflammatory } \\
\text { systems }\end{array}$ & $\begin{array}{l}\text { Growth-factor } \\
\text { enhancement system }\end{array}$ \\
\hline Tetracycline-CH & $\begin{array}{l}\text { Glutaraldehyde } \\
\text {-CH }\end{array}$ & Mannitol-CH & Betamethasone-CH & Laminin-CH \\
\hline Neomycin-CH & Cisplatin-CH & Calcitonin-CH & Acetonide-CH & Albumin-CH \\
\hline Cloxacillin-CH & $\begin{array}{l}\text { Mifepristone- } \\
\text { CH }\end{array}$ & Insulin-CH & Indomethacin-CH & BMP7-CH \\
\hline $\begin{array}{l}\text { Tetrachlorocycli } \\
\text { n-CH }\end{array}$ & $\begin{array}{l}\text { Trastuzumab- } \\
\text { CH }\end{array}$ & Alginate-CH & Triamcinolone-CH & Chondroitin-CH
\end{tabular}

\subsection{The antimicrobial properties of chitosan.}

The antimicrobial activity of chitin, $\mathrm{CH}$, and their bi-products against various microorganisms such as fungi, bacteria, yeast, and algae has revealed impactful results because of their characteristic properties. Generally, $\mathrm{CH}$ can be used alone or mixed with other compounds to show its antimicrobial actions [33]. There are two antimicrobial mechanisms of $\mathrm{CH}$. The foremost mechanism deals with the polycationic structure that inhibits bacterial cell wall, impairs the cellular functioning, and finally cause cell death. The second mechanism concerns the hindrance in central dogma; transcription is affected when chitosan binds to bacterial DNA. Soluble chitosan demonstrated better antimicrobial properties compared with $\mathrm{CH}$ oligomers, it uniquely suppressed Gram +ve and Gram -ve bacterial growth (Figure 4). Based upon the molecular weight, $\mathrm{CH}$ can suppress specific microbes and fungi, $0.1 \%$ solution along with $0.75 \%$ acetic acid was more effective against Gram -ve bacteria rather than Gram +ve. Yet, lactic acid bacteria are inhibited by the solution of $1 \%$ methanoic acid [34]. Few examples of microbial species that were restrained using $\mathrm{CH}$ solution are $F$. acuminatum, Cylindrocladium floridanum, Saprolegnia parasitica, and so on [35]. Similarly, CH was demonstrated to be bactericidal on different microbial species summed up in (Table 4), indicating the minimum inhibitory concentrations (MICs) of microorganisms. Today biofilms and composite nanofibers of $\mathrm{CH}$ are manufactured by electrospinning technology with great morphological characteristics and diameter across $250 \mathrm{~nm}$ to $390 \mathrm{~nm}[36,37]$. Many other antibacterial composite nanofibers are also being developed to give more effective results.

Table 4. Minimal inhibitory concentration (MIC) of chitosan against different microbes.

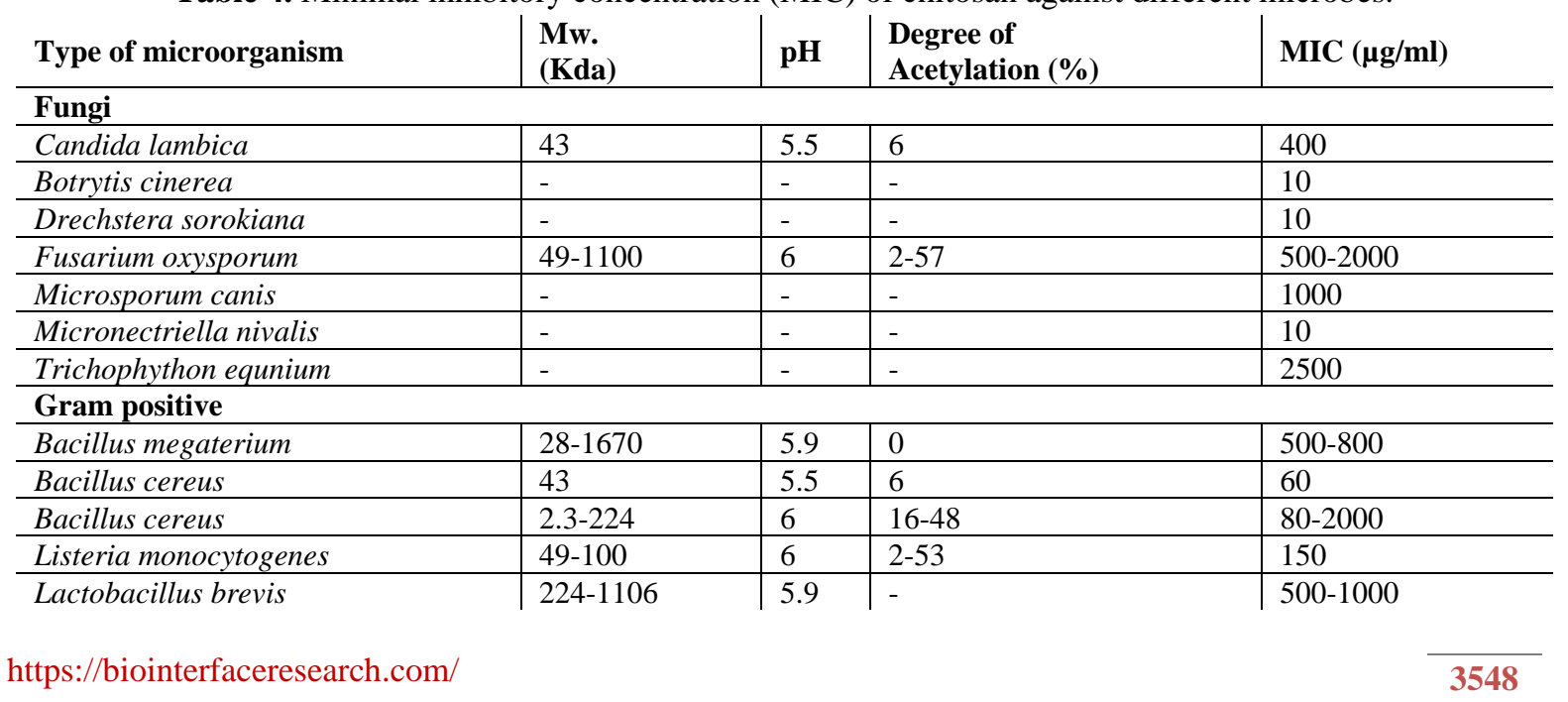




\begin{tabular}{l|l|l|l|l} 
Type of microorganism & $\begin{array}{l}\text { Mw. } \\
(\mathbf{K d a})\end{array}$ & $\mathbf{p H}$ & $\begin{array}{l}\text { Degree of } \\
\text { Acetylation }(\%)\end{array}$ & MIC $(\boldsymbol{\mu g} / \mathbf{m l})$ \\
\hline Lactobacillus bulgaricus & $28-1670$ & 5.9 & - & up to 1000 \\
\hline Staphylococcus aureus & $28-1106$ & 5.9 & - & $800-10000$ \\
\hline Gram negative & $49-1100$ & 6 & - & $100-500$ \\
\hline Escherichia coli & $28-1670$ & 5.9 & $2-53$ & $800-1000$ \\
\hline Escherichia coli & $3-224$ & 6 & $16-48$ & $30-2000$ \\
\hline Escherichia coli & 43 & 5.5 & 6 & 60 \\
\hline Enterobacter aerogenes & $49-1100$ & 6 & $2-53$ & $150-200$ \\
\hline Pseudomonas aeruginosa & 43 & 5.5 & 6 & 80 \\
\hline Pseudomonas fluorescens & $49-1670$ & 6 & $2-53$ & $1500-2000$ \\
\hline Salmonella typhimurium & $49-1100$ & 6 & $2-53$ & 200
\end{tabular}

Gram negative bacteria

Outer membrane
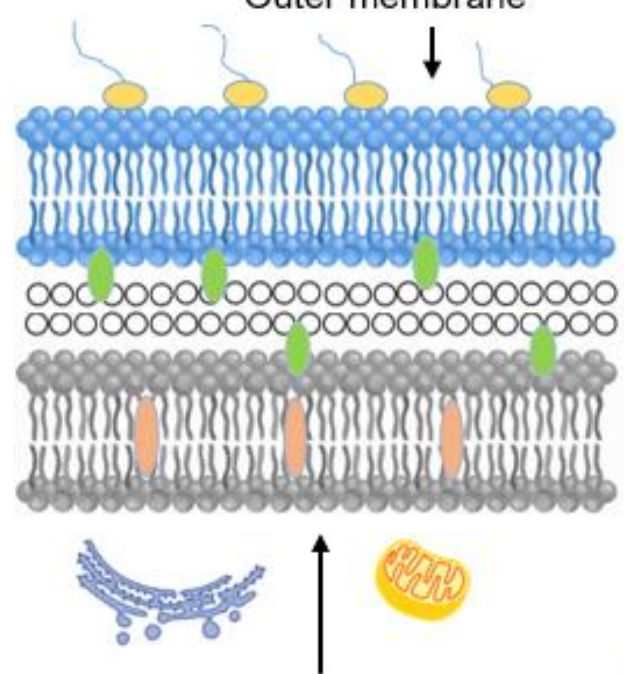

Cytoplasmic membrane<smiles>CCCCCCCCCCCCC</smiles>

Blockage of nutrient flow

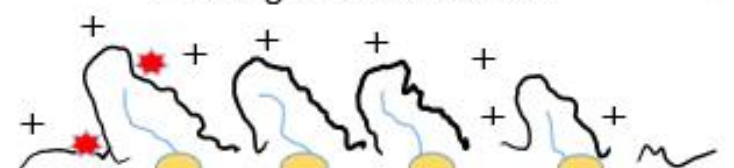

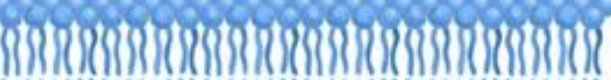

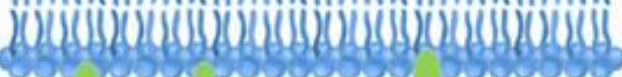

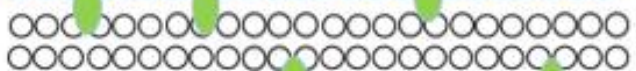

ం,000000000 00000000000

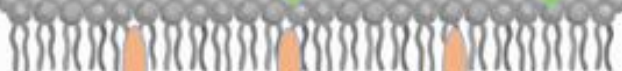

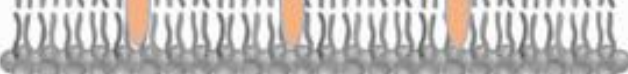
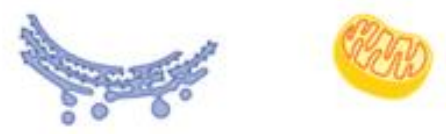

Gram positive bacteria

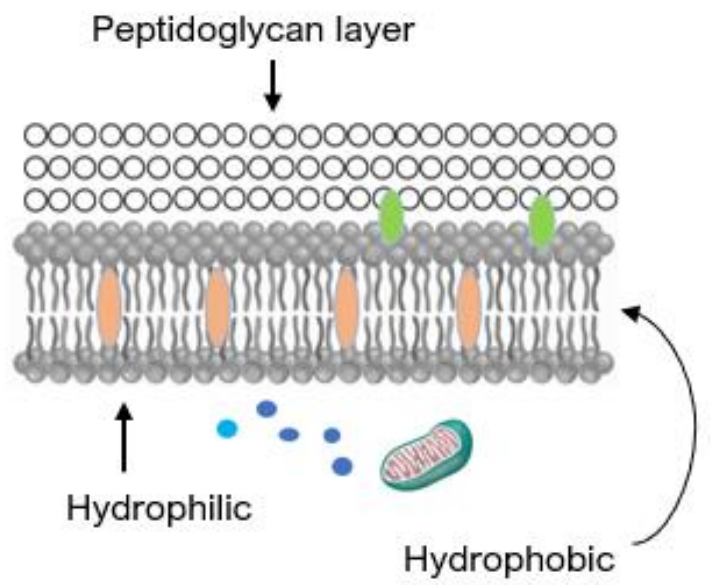

CHITOSAN

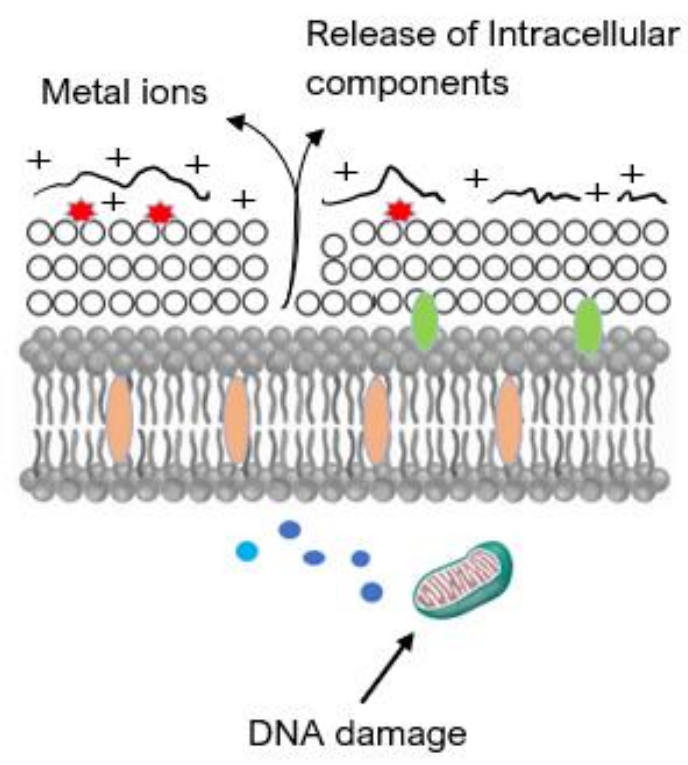

Figure 4. Antimicrobial action of chitosan on DNA of gram-positive and gram-negative bacteria causing the inhibition of mRNA due to its polycationic nature. 


\subsection{Chitosan as a tissue engineering scaffolds.}

Utilizing chitosan, many tissues engineered products have been designed, and their physicochemical properties are re-established for improved functioning. It involves nuclear reprogramming and structuring of new cells using pre-existing cells. Due to the biodegradability and nontoxicity of $\mathrm{CH}$, it can be modified into fiber, film, sponge, and hydrogels. Tissue-engineered $\mathrm{CH}$ is utilized in repairing a section or entire tissue, blood vessels, bone, skin, cartilage, bladder, damaged muscles, etc. At current, $\mathrm{CH}$-built biomaterials are the mainstream focus being developed for regenerative medicine. The phosphorylated $\mathrm{CH}$ in conjunction with calcium phosphate is used for bone treatment. It is an ideal polymer shaped into the desirable scaffold, artificial skin grafts, or nanocomposites. Lignin/chitosan-PVA composite hydrogel biopolymeric dressings have prominent wound contraction ability, and when applied on an open wound surface, they maintained good antioxidant and antibacterial properties [38]. Several artificial tissues have been readied, such as cartilage and nerve tissues and the most common artificial dermal tissue. In bone tissue engineering $\mathrm{CH}$ facilitates osteoblast cell culturing for producing mineral-rich matrix. $\mathrm{CH}-\beta$-tricalcium phosphate complex expressed efficacious results in promoting osteogenesis, vascularization, and repairing bone deformities related to mesenchymal stem cells. Autografts and allografts have been deployed for long bone segmental defects [39-41]. For the treatment of chronic skin ulcer, sponge dressings composed of chitosan glutamate and sericin was optimized and formulated [42]. The fibrillar network of sponges indicated advantageous results in tissue repair application. In the year 2009, supercritical $\mathrm{CO}_{2}$ was utilized to prompt permeability in chitosan scaffolds, making them porous for maximum absorptive capacity [43]. The sponges made up of chitosan were also crosslinked with antibiotics like norfloxacin, levofloxacin using the solvent evaporation method for antimicrobial action. Nanofibrous scaffolds have improved osteoinductive effects compared with pure chitosan films after culturing for 7 days in-vitro [44, 45].

\subsection{The anticancer activities of chitosan.}

Among many incurable diseases, cancer is considered to be the most lethal and lifethreatening disease. Many treatments are available to eliminate tumor cells from the body, like chemotherapy, including drug treatment, which arrests the cell cycle to stop the abnormal, excessive, and uncontrolled growth of cancerous cells. [46]. This execution also incorporates few noncancerous cells, for example, bone marrow, gut epithelia, lymph cells, RBSs, and hair follicles. The fundamental challenge in the existing chemotherapy treatment is drug toxicity to the body's healthy organs because of non-selectivity and non-specificity. Furthermore, chemotherapeutic agents may cause serious side effects, thereby limiting viable medical care and the life of patients. Relevant possibilities have been designed to overcome this problem, which is lodged with biopolymeric pathways and consists of polymer-based anticancer medications. In-vitro and in-vivo studies were carried out to evaluate the performance of chitosan and its derivatives as antitumor agents. Experimental data indicated anticancer activity of chitosan, the main mechanism behind this was an increase in the release of IL-1 and IL-2, causing invasion of T-cell lymphocytes. Besides that, it was shown that micelle-paclitaxel conjugated chitosan is dynamic for the high production of lymphokines and the development of cytolytic T lymphocytes [47]. Numerous investigations stated that chitosan was associated with obliteration of cancerous cells by initiating programmed cell death (apoptosis). It hinders 
the attachment of primary melanoma A375 cells, prevents the growth of melanoma SKMEL28 cells and refined neurolemma cells. In epithelial ovarian cancer, chitosan nanoparticles (NPs) delivering mEZH2 siRNA have a perceptible impact on the tumor's vasculature along with other features such as inhibitory effects on the proliferation of cells [48]. When siRNA is combined with chitosan NPs and docetaxel, it inhibits tumor cells [49].

\subsection{Usefulness of marine collagen in artificial skin grafts.}

Regardless of their medical significance, skin grafts have many limitations like adverse immune response, graft rejection, and donor availability. Over the years, an increase in the need for skin replacements for the permutation of skin damages caused due to injury, burns, blow, scars, contamination, mutations, and different ailments turned into a serious healthcare problem. Therefore, marine collagen-based artificial grafts have been developed from different marine sources such as fishes, sea-urchins, ocean lobsters, and jellyfish with minimal side effects and influential properties [50]. There are four stages of wound healing in humans. Skin grafts developed with fish collagen play an important function in each step of the healing process. Hemostasis is the primary stage of wound healing; it starts right away after an injury and causes the stoppage of bleeding. In hemostasis, various factors are released by the degranulating thrombocytes and by the substance released by damaged tissue cells like IGF-I, PDGF, TGF- $\beta$, and EGF and followed by coagulation cascade. During the inflammatory stage, penetrability is expanded to improve adherence of cells for wound contraction. The migration and proliferation stages are characterized by angiogenesis, epithelisation, and fibroplasia. The final stage of healing, called remodeling, also known as the maturation phase, starts after 21 days post-injury and can last for two years. During this stage, the composition of the matrix also changes; collagen organization takes place utilizing collagenase, elastase, and MMPs. Efficacious tissue repair is important to facilitate homeostasis and to stop microbial infection $[51,52]$. Collagen was extracted from the skin of marine big eye snapper Priacanthus humor. The mechanical spinning method was employed to crosslink polymers and fabricate scaffolds as artificial tissue [53].

\subsection{Usefulness of marine collagen in skin regeneration.}

The tissue repair activity of poly (3-hydroxy butyrate-co-4-hydroxy butyrate) scaffolds was determined by conjugation of its amine surface with marine collagen peptide (MCP) obtained from tilapia skin [54]. These $\mathrm{P}(3 \mathrm{HB}-\mathrm{co}-4 \mathrm{HB}) / \mathrm{MCP}$ scaffolds have improved the adhesion and distribution of mouse fibroblast cells (L929) and had a prominent influence on wound stenosis, proposing that this tissue-engineered scaffold can be a future platform for wound healing advancements. Mrigal fish (Cirrhinus cirrhosis) scales were also utilized for the production of collagen scaffold by means of the lyophilization technique [55]. It has been observed that modified scaffolds advanced human fibroblasts and keratinocyte multiplication. Collagen gel matrix was formulated using centrifugation technique, utilization of EDC crosslinking polymer using pepsin soluble collagen separated from the skin of Leiocassis longirostris and Nile tilapia (Oreochromis niloticus) [56]. Pepsin soluble collagen from the skin of Lophius litulo showed antioxidative and wound mending characteristics on ICR strain mice [57]. This scaffold not only have superior biocompatibility for the activity and proliferation of the mouse embryonic fibroblasts (MEFs) in vitro, yet in addition, it prevented cerebrum tissue adhesion, reduced inflammation, enabled fibroblasts growth and improved the 
tissue recovery in the in-vivo rabbit dural defect model, indicating that these scaffolds can be utilized successfully as engineered dural substitutes. In the rat uterine wound model, MCP from chum salmon skin improved the tensile strength of skin and uterine bursting pressure. It enhanced hydroxyproline limits, facilitated capillary formation and growth of new fibroblasts and collagen bundles [58]. This investigation stated better organization of extracellular membrane (ECM) segments due to expression of growth factors like TGF- $\beta 1$ and bFGF, respectively. Clinical advancements are in progress to accelerate tissue repair and regeneration.

\subsection{Usefulness of marine collagen in targeted drug delivery.}

Drug delivery of large size molecules to a specific site is a major issue affecting bioavailability, solvency, and absorption of the drug in the body tissues. Therefore, utilization of targeted drug delivery systems specific to body organs is possibly a choice that may comprehend these challenges. Today, nanotechnology assumes a crucial job in new medications, and their targeted delivery with controlled-release has been a big achievement [59]. A number of researches have indicated that marine collagen is a suitable material for drug carriers in controlled release systems. In silver carp skin, tissue engineering marine collagen and chondroitin sulfate scaffolds were constructed by freeze-dried technique and merged with bFGF-loaded PLG micro particulates. These scaffolds expressed a regulated release rate that depended upon the proportion of marine collagen within the scaffold and was biologically compatible. They promoted fibroblasts for skin tissue recovery, thus representing that scaffolds designed using marine life collagen can be utilized for targeted delivery systems for wound mending. Utilizing Synodontidae fish scales and MCP, chelated calcium alginate nanoparticles of $400 \mathrm{~nm}$ in diameter were encapsulated [60]. The in vivo studies demonstrated that MCPbased calcium chelated complex nanoparticles enhanced calcium uptake impeding calcium deficiency, expanded femoral bone mineral density in rats, and recommended that it be an ideal transporter of calcium. The appropriateness of collagen gels and films synthesized utilizing acid-soluble collagen and pepsin soluble collagen from the eel fish (Evenchelys macrura) skin were examined for holding drugs like amoxicillin and tetracycline acting as active carriers for antibacterial drugs [61]. An injectable combination of chitosan and marine collagen gel was also formed utilizing scales of Chum salmons (Oncorhynchus keta) and was infused in rats via a subcutaneous route. Results indicated that the release of TNF- $\alpha$ was progressively controlled with the incursion of other inflammatory mediators [62].

\subsection{Usefulness of marine collagen in cosmetic and medical applications.}

Collagen has now been recognized for its pharmacological activity having great possibilities in the field of cosmetics. The search for safer and cost-effective medicinal products is consistent. Particularly, marine proteins these days are being introduced as excellent API for the cosmetic industry. For example, its characteristics like anti-aging, UV protection take to the advancement of ointments and gels with effective nourishing activity. From a cosmetic point of view, marine collagen is acquired from scales and body of cold-water fishes, for example, codfish, pollack, Tilapia nilotica, Salmo salar, and salmon; through enzymatic hydrolysis technique, the peptides obtained from scales of these fishes could accelerate the wound healing process via upregulation of $\beta$-defensin and nucleotide-binding oligomerization domain-2. Also, oral collagen intake for four weeks improved skin texture, elasticity, and sunburn [63, 64]. Oral administration of active peptides from Pinctada martensii has resulted 
in improved skin wounds [65]. Collagen products in cosmetics are utilized for retaining moisture and heat loss from the injured site while shielding the wound from microbial attack and regenerating new tissues $[66,67]$. Furthermore, vitamin-C eye gel with collagen is being utilized in ophthalmology as shields, micro-capsules, tablets for drug delivery, gels combined with liposomes for transdermal patches, and nanoparticles for genetic engineering technology. Currently, a collagen-based scaffold presumes an imperative job. It is limited to heal wounds and supports ligament and bone remodeling influenced by stem cells. Scaffolding materials are implanted in cases of traumatic injury, grafts or evasion, burns, severe cut impact, etc. Collagen has different applications: in the cardiovascular system, collagen as an artificial blood vessel is grafted in patients with successful outcomes, in urological \& genital diseases, corneal defects (contact lenses), neural migration, dental applications, osteoarthritis, and obese morbidities $[68,69]$. Marine collagen, particularly from blue shark scales, is combined with chitosan for synergistic effects and used as a preservative as a composite coating [70]. MCP from Nibea japonica stimulates cell proliferation and migration of embryonic fibroblast cells from the mice NIH-3T3 via an NF-KB signaling pathway that aids in wound repair [71, 72].

\subsection{Usefulness of marine collagen in dental and corneal tissue engineering.}

The skeleton of a human tooth is distinctive, composed of several hard and soft tissues such as tooths, maxilla, mandible, and gums. In recent years, a great advancement has been observed in the field of regenerative dental and corneal tissue engineering [73]. Fish collagen obtained from the skin of tilapia (Oreochromisniloticus) advanced cell suitability, improved alkaline phosphatase functioning and tuned the expression of genes in bone sialoprotein of mice odontoblast like cells (MDPC-23). It has also stepped up matrix concretion similar to that of porcine skin, suggesting type II collagen's applicability in dentistry for dentin-pulp recovery [74]. The use of MCP in osteogenic differentiation advanced the growth of human periodontal ligament (hPDL) cells and upregulated the expression of osteogenic markers using the ERK signaling pathway, proposing that $\mathrm{MCP}$ is a bioactive pharmaceutical utilized in alveolar bone recovery [75]. Secondly, Corneal damage is the major reason for visual impairment around the globe. Keratoplasty using solid tissue transplant is the surgical treatment of cornea when vision cannot be rectified with different medicines. This is the most appropriate method accepted globally. However, there is a shortage of cornea donors which tends to be a common issue. But researchers are focusing on treating corneal infection and vision recovery by incorporating marine collagen and its bi-products to minimize vision loss. A decellularized and de-calcified fish skin-originated collagen matrix was suggested as an option for corneal tissue donors [76]. MC-based matrix has been implanted in the ocular membrane of a rat model in front lamellar keratoplasty indicated sufficient light transmission, practical light-emitting value, and improved eyesight recommending marine collagen for a corneal transplant to tackle the scarce of cornea donors.

\section{Conclusions}

In the current scenario, biopolymers are assuming a prime job in the pharmaceutical and biomedical fields. Marine collagen and chitosan and their combinations have been introduced as perfect sustainable biomaterial to develop antimicrobial wound dressings, either alone or bettered by means of some drug incorporation and combined with antibiotics, natural compounds, or plant extracts. They both act as the most promising biomaterials and have 
versatile pharmacological applications, for example, wound care, tissue engineering, sponge, scaffold, nanofibers, absorbable surgical sutures, and drug release kinetics. Significant evidence has demonstrated that collagen and chitosan-based therapeutic agents are broadly utilized in the pharmaceutical industry as microparticles, biologicals, shields in ophthalmology sponges, and many others. These agents have the ability to manipulate the pathophysiology and biochemistry of wound surfaces at the cellular level. Numerous scientific reports and researches indicate the capability of marine collagen and chitosan from small-scale use to largescale production, the power to the scaffold, in case of severe bleeds, these are supreme bioactive molecules. Another biomedical application is targeted drug delivery, where chitosan and marine collagen as nano-biodegradable carriers play an essential role. These biomaterials are widely used in today's clinical practices and are supposed to influence developing pharmacological approaches significantly.

\section{Funding}

This research received no external funding.

\section{Acknowledgments}

The team of authors thanks to the Institute of Nuclear Medicine and Allied Sciences, Defence Research \& Development Organisation, New Delhi, for giving an idea to research and survey the biomaterials employed in this review.

\section{Conflicts of Interest}

The authors declare no conflict of interest.

\section{References}

1. Cruz, M.A.; Araujo, T.A.; Avanzi, I.R.; Parisi, J.R.; de Andrade, A.L.M.; Rennó, A.C.M. Collagen from Marine Sources and Skin Wound Healing in Animal Experimental Studies: a Systematic Review. Mar Biotechnol 2021, 23, 1-11, https://doi.org/10.1007/s10126-020-10011-6.

2. Elgadir, M.A.; Uddin, M.S.; Ferdosh, S.; Adam, A.; Chowdhury, A.J.K.; Sarker, M.Z.I. Impact of chitosan composites and chitosan nanoparticle composites on various drug delivery systems: A review. J. Food Drug Anal 2015, 23, 619-629, https://doi.org/10.1016/j.jfda.2014.10.008.

3. Pang, Y.; Qin, A.; Lin, X.; Yang, L.; Wang, Q.; Wang, Z.; Shan, Z.; Li, S.; Wang, J.; Fan, S. Biodegradable and biocompatible high elastic chitosan scaffold is cell-friendly both in vitro and in vivo. Oncotarget 2017, 8, 35583-91, https://doi.org/10.18632/oncotarget.14709.

4. Scalera, F.; Monteduro, A.G.; Maruccio, G.; Blasi, L.; Gervaso, F.; Mazzotta, E.; Malitesta, C.; Piccirillo, C. Sustainable chitosan-based electrical responsive scaffolds for tissue engineering applications, Sustain. Mater. Technol. 2021, 28, e00260, https://doi.org/10.1016/j.susmat.2021.e00260.

5. Parhi, R. Drug delivery applications of chitin and chitosan: a review. Environ Chem Lett 2020, 18, 577-594, https://doi.org/10.1007/s10311-020-00963-5.

6. Jing, S-B.; Li, L.; Ji, D.; Takiguchi, Y.; Yamaguchi, T. Effect of Chitosan on Renal Function in Patients with Chronic Renal Failure. J. pharm. Pharmacol. 1997, 49, 721-3, https://doi.org/10.1111/j.20427158.1997.tb06099.x.

7. Husain, S.; Al-Samadani, K.H.; Najeeb, S.; Zafar, M.S.; Khurshid, Z.; Zohaib, S.; Qasim, S.B. Chitosan biomaterials for current and potential dental applications. Materials 2017, 10, 602, https://doi.org/10.3390/ma10060602.

8. Wahba, M.I. Sodium bicarbonate-gelled chitosan beads as mechanically stable carriers for the covalent immobilization of enzymes. Biotechnol. Prog. 2018, 34, 347-361, https://doi.org/10.1002/btpr.2587.

9. Goy, R.C.; Britto, D.d.; Assis, O.B. A review of the antimicrobial activity of chitosan. Polímeros 2009, 19, 241-247, https://doi.org/10.1590/S0104-14282009000300013.

10. Kong, Y.; Tang, X.; Zhao, Y.; Chen, X.; Yao, K.; Zhang, L.; Han, Q.; Zhang, L.; Ling, J.; Wang, Y.; Yang, Y. Degradable tough chitosan dressing for skin wound recovery. Nanotechnol. Rev. 2020, 9, 1576-1585. https://doi.org/10.1515/ntrev-2020-0105. 
11. Wei, X.; Ding, S.; Liu, S.; Yang, K.; Cai, J.; Li, F.; Wang, C.; Lin, S.; \& Tian, F. Polysaccharides-modified chitosan as improved and rapid hemostasis foam sponges. Carbohydrate polymers 2021, 264, 118028, https://doi.org/10.1016/j.carbpol.2021.118028.

12. Coppola, D.; Oliviero, M.; Vitale, G.A.; Lauritano, C.; D’Ambra, I.; Iannace, S.; de Pascale, D. Marine Collagen from Alternative and Sustainable Sources: Extraction, Processing and Applications. Mar. Drugs 2020, 18, 214, https://doi.org/10.3390/md18040214.

13. Skierka, E.; Sadowska, M. The influence of different acids and pepsin on the extractability of collagen from the skin of baltic cod (Gadus morhua). Food Chem. 2007, 105, 1302-1306, https://doi.org/10.1016/j.foodchem.2007.04.030.

14. Silva, T.H.; Moreira-Silva, J.; Marques, A.L.; Domingues, A.; Bayon, Y.; Reis, R.L. Marine origin collagens and its potential applications. Mar Drugs 2014, 12, 5881-5901, https://doi.org/10.3390/md12125881.

15. Subhan, F.; Ikram, M.; Shehzad, A.; Ghafoor, A. Marine Collagen: An Emerging Player in Biomedical applications. Journal of food science and technology 2015 , 52, 4703-7, https://doi.org/10.1007/s13197-0141652-8.

16. Lima, J.M.D.; Sarmento, R.R.; Souza, J.R.D.; Brayner, F.A.; Feitosa, A.P.S.; Padilha, R.; Alves, L.C.; Porto, I.J.; Batista, R.F.B.D.; Oliveira, J.E.D.; Medeiros, E.S.D.; Bonan, P.R.F.; Casteallano, L.R. Evaluation of Hemagglutination Activity of Chitosan Nanoparticles Using Human Erythrocytes, BioMed Research International 2015, https://doi.org/10.1155/2015/247965.

17. Fan, W.; Yan, W.; Xu, Z.; Ni, H.; Erythrocytes load of low molecular weight chitosan nanoparticles as a potential vascular drug delivery system. Colloids Surf B Biointerfaces 2012, 95, 258-65, https://doi.org/10.1016/j.colsurfb.2012.03.006.

18. Okamoto, Y.; Yano, R.; Miyatake, K.; Tomohiro, I.; Shigemasa, Y.; Minami, S. Effects of chitin and chitosan on blood coagulation. Carbohydrate Polym. 2003, 337-342, https://doi.org/10.1016/S0144-8617(03)000766.

19. Joshi, R.; Collagen Biografts for Chronic Wound Healing. In: Collagen Biografts for Tunable Drug Delivery. SpringerBriefs in Applied Sciences and Technology. Springer, Cham. 2021, https://doi.org/10.1007/978-3030-63817-7_4.

20. Sivashankari, P.; Prabaharan, M. Prospects of chitosan-based scaffolds for growth factor release in tissue engineering. Int. J. Biol. Macromol. 2016, 93, 1382-1389, https://doi.org/10.1016/j.ijbiomac.2016.02.043.

21. Misgav, M.; Lubetszki, A.; Brutman-Barazani, T.; Martinowitz, U.; Kenet, G. The hemostatic efficacy of chitosan-pads in hemodialysis patients with significant bleeding tendency. J. Vasc. Access 2017, 18, 220224, https://doi.org/10.5301/jva.5000707.

22. Ahmed, T.A.; Aljaeid, B.M. Preparation, characterization, and potential application of chitosan, chitosan derivatives, and chitosan metal nanoparticles in pharmaceutical drug delivery. DrugDes. Dev. Ther. 2016, 10, 483, https://doi.org/10.2147/DDDT.S99651.

23. Yang, H.; Chen, Y.; Chen, Z.; Geng, Y.; Xie, X.; Shen, X.; Li, T.; Li, S.; Wu, C.; Liu, Y. Chemophotodynamic combined gene therapy and dual-modal cancer imaging achieved by $\mathrm{pH}$-responsive alginate/chitosan multilayer- modified magnetic mesoporous silica nano composites. Biomater. Sci. 2017, 5 , 1001-1013, https://doi.org/10.1039/C7BM00043J.

24. Rodrigues, S.V.; John, L.E.; Mitra, D.K.; Shah, R.; Shetty, G.; Prithyani, S.; Vijayakar, H. Evaluation and Comparison of Antimicrobial Effects of Chlorhexidine (CHX) and Chitosan (CHT) Mouthwash in Chronic Periodontitis (CGP) Patients-A Clinico-microbiological Study. JIDA J. Indian Dent. Assoc. 2018, 16, 26-32, https://dx.doi.org/10.9790/0853-1610042632.

25. Wei, S.; Ching, Y.C.; Chuah, C.H.; Synthesis of chitosan aerogels as promising carriers for drug delivery: A review, Carbohydrate Polymers 2020, 231, https://doi.org/10.1016/j.carbpol.2019.115744.

26. Hejazi, R.; Amiji, M.; Stomach-specific anti-H pylori therapy. II. Gastric residence studies of tetracyclineloaded chitosan microspheres in gerbils. Pharm Dev Technol 2003, 8, 253-262, https://doi.org/10.1081/pdt120022154.

27. Wei, W.; Behloul, N.; Wang, W.; Baha, S.; Liu, Z.; Shi, R.; Meng, J. Chitosan Nanoparticles Loaded with Truncated ORF2 Protein as an Oral Vaccine Candidate against Hepatitis E. Macromol. Biosci. 2021, 21, 2000375, https://doi.org/10.1002/mabi.202000375.

28. Nagamoto, T.; Hattori, Y.; Takayama, K.; Maitani, Y. Novel chitosan particles and chitosancoated emulsions inducing immune response via intranasal vaccine delivery. Pharm Res. 2004, 21, 671-674, https://doi.org/10.1023/B:PHAM.0000022414.17183.58.

29. Parmaksız, S.; Şenel, S. An Overview on Chitosan-Based Adjuvant/Vaccine Delivery Systems. In: Advances in Polymer Science. Springer, Berlin, Heidelberg. https://link.springer.com/chapter/10.1007/12_2021_93.

30. Aggarwal, A.; Kaur, S.; Tiwary, A.K.; Gupta, S. Chitosan microspheres prepared by an aqueous process: release of indomethacin. J Microencapsul 2001, 18, 819-823, https://doi.org/10.1080/02652040110065495.

31. Wang, J.; Zhang, C.; Guo, C.; Li, X. Chitosan Ameliorates DSS-Induced Ulcerative Colitis Mice by Enhancing Intestinal Barrier Function and Improving Microflora. Int. J. Mol. Sci. 2019, 20, 5751, https://doi.org/10.3390/ijms20225751. 
32. Suh, J.K.; Matthew, H.W.; Application of chitosan-based polysaccharide biomaterials in cartilage tissue engineering: a review. Biomater 2000, 21, 2589-259, https://doi.org/10.1016/s0142-9612(00)00126-5.

33. Si, Z.; Hou, Z.; Vikhe, Y. S.; Thappeta, K.; Marimuthu, K.; De, P. P.; Ng, O. T.; Li, P.; Zhu, Y.; Pethe, K.; \& Chan-Park, M. B. Antimicrobial Effect of a Novel Chitosan Derivative and Its Synergistic Effect with Antibiotics. ACS applied materials \& interfaces 2021, 13, 3237-3245, https://doi.org/10.1021/acsami.0c20881.

34. Liu, X.F.; Guan, Y.L.; Yang, D.Z.; Li, Z.; Yao, K.D. Antibacterial action of chitosan and carboxymethylated chitosan. J Appl Polym Sci. 2001, 79, 1324-1335, https://doi.org/10.1002/10974628(20010214)79:7<1324::AID-APP210>3.0.CO;2-L.

35. Cheung, R.C.; Ng. T.B.; Wong, J.H.; Chan, W.Y. Chitosan: an update on potential biomedical and pharmaceutical applications. Mar Drugs 2015, 13, 5156-5186, https://doi.org/10.3390/md13085156.

36. Khan, F.; Pham, D.T.N.; Oloketuyi, S.F.; Manivasagan, P.; Oh, J. Kim Y-Mog. Chitosan and their derivatives: Antibiofilm drugs against pathogenic bacteria, Colloids and Surfaces B: Biointerfaces 2019, https://doi.org/10.1016/j.colsurfb.2019.110627.

37. De Silva, R.T.; Mantilaka, M.M.; Ratnayake, S.P.; Amaratunga, G.A.; de Silva, K.N. Nano-MgO reinforced chitosan nanocomposites for high performance packaging applications with improved mechanical, thermal and barrier properties. Carbohydr Polym 2017, 157, 739-747, https://doi.org/10.1016/j.carbpol.2016.10.038.

38. Da-feng Zheng; Ling, Hu.; and Xue-qing Qiu. Recent Advances in Lignin-Based Hydrogels and Its Synthesis and Applications. Lignin Utilization Strategies: From Processing to Applications 2021 , 207-229, https://doi.org/10.1021/bk-2021-1377.ch009.

39. Yang, L.; Wang, Q.; Peng, L.; Yue, H.; Zhang, Z. Vascularization of repaired limb bone defects using chitosan- $\beta$-tricalcium phosphate composite as a tissue engineering bone scaffold. Mol Med Rep. 2015, 12, 2343-2347, https://doi.org/10.3892/mmr.2015.3653.

40. Dai, T.; Tanaka, M.; Huang, Y.Y.; Hamblin, M.R. Chitosan preparations for wound sand burns: antimicrobial and wound-healing effects. Exp Rev Anti-infect Therapy 2011, 9, 857-879, https://dx.doi.org/10.1586\%2Feri.11.59.

41. Zhang, M.; Matinlinna, J.P.; Tsoi, J.K.; Liu, W.; Cui, X.; Lu, W.W.; Pan, H. Recent developments in biomaterials for long-bone segmental defect reconstruction: A narrative overview, Journal of Orthopaedic Translation 2019, 22, 26-33, https://doi.org/10.1016/j.jot.2019.09.005.

42. Mehreen, E.; Shaukat, A.; Hafiz, M. T.; Rabia, M.; \& Muhammad F. B. Sericin and fibroin nanoparticles natural product for cancer therapy: a comprehensive review, International Journal of Polymeric Materials and Polymeric Biomaterials 2021, 70, 256-269, https://doi.org/10.1080/00914037.2019.1706515.

43. Kumari, R.; Shipra, T.; Dutta, P.K.; Dutta, J.; Hunt, A.J.; Macquarriec, D.J.; Clark, J.H. Direct chitosan scaffold formation via chitin whiskers by a supercritical carbon dioxide method: a green approach. J. Mater. Chem. 2009, 19, 8651-8655, https://doi.org/10.1039/B910842D.

44. Panoraia, I.S.; Asimina, P.Z.; Maria, K.M.; Ioannis, D.K.; Dimitrios, N.B. Porous dressings of modified chitosan with poly(2-hydroxyethyl acrylate) for topical wound delivery of levofloxacin. Carbohydr. Polym. 2016, 143, 90-99, https://doi.org/10.1016/j.carbpol.2016.02.009.

45. Tao, F.; Cheng, Y.; Shi, X.; Zheng, H.; Du, Y.; Xiang, W.; \& Deng, H. Applications of chitin and chitosan nanofibers in bone regenerative engineering. Carbohydrate Polymers 2020, 230, 115658, https://doi.org/10.1016/j.carbpol.2019.115658.

46. Zhang, X.; Yang, X.; Ji, J.; Liu, A.; Zhai, G. Tumor targeting strategies for chitosan-based nanoparticles. Colloids Surf B Biointerfaces 2016, 148, 460-473, https://doi.org/10.1016/j.colsurfb.2016.09.020.

47. Emami, J.; Rezazadeh, M.; Hasanzadeh, F.; Sadeghi, H.; Mostafavi, A.; Minaiyan, M.; Rostami, M.; Davies, N. Development and in vitro/in vivo evaluation of a novel targeted polymeric micelle for delivery of paclitaxel. Int J Biol Macromol 2015, 80, 29-40, https://doi.org/10.1016/j.ijbiomac.2015.05.062.

48. Chamani, M.; Maleki; Dana, P.; Chaichian, S.; Moazzami, B.; Asemi, Z. Chitosan is a potential inhibitor of ovarian cancer: Molecular aspects. IUBMB Life. 2019, https://doi.org/10.1002/iub.2206.

49. Cheng, C.J., Bahal, R., Babar, I.A., Pincus, Z., Barrera, F., Liu, C., Svoronos, A., Braddock, D.T., Glazer, P.M., Engelman, D.M., Saltzman, W.M. MicroRNA silencing for cancer therapy targeted to the tumour microenvironment. Nature 2015, 518, 107-110, https://doi.org/10.1038/nature13905.

50. Ferrario, C.; Rusconi, F.; Pulaj, A.; Macchi, R.; Landini, P.; Paroni, M.; Colombo, G.; Martinello, T.; Melotti, L.; Gomiero, C.; Candia Carnevali, M.D.; Bonasoro, F.; Patruno, M.; Sugni, M. From Food Waste to Innovative Biomaterial: Sea Urchin-Derived Collagen for Applications in Skin Regenerative Medicine. Mar. Drugs 2020, 18, 414, https://doi.org/10.3390/md18080414.

51. Sitje, T.S.; Grøndahl, E.C.; Sørensen, J.A. Clinical innovation: Fish-derived wound product for cutaneous wounds. Wounds Int. 2018, 9, 44-50, https://www.woundsinternational.com/resources/details/clinicalinnovation-fish-derived-wound-product-cutaneous-wounds.

52. Wolcott, R.; Fletcher, J. The role of wound cleansing in the management of wounds. Wounds Int. 2014, 1, 25-31, https://www.woundsinternational.com/resources/details/the-role-of-wound-cleansing-in-themanagement-of-wounds.

53. Rajasree, R.S.R.; Gobalakrishnan, M.; Aranganathan L.; Karthih, M.G. Fabrication and characterization of chitosan-based collagen/ gelatin composite scaffolds from big eye snapper Priacanthus hamrur skin for 
antimicrobial and antioxidant applications, Materials Science \& Engineering C 2020, 107, 110270, https://doi.org/10.1016/j.msec.2019.110270.

54. Shang, Y.; Yao, S.; Qiao, X.; Wang, Z.; Zhao, X.; Huang, Z.; Gu, Q.; Wang, N.; Peng, C. Evaluations of Marine Collagen Peptides from tilapia skin on experimental oral ulcer model of mice. Materials Today Communications 2021, 26, 101893, https://doi.org/10.1016/j.mtcomm.2020.101893.

55. Ullah, S.; Zainol, I.; Chowdhury, S.R.; Fauzi, M.B. Development of various composition multicomponent chitosan/fish collagen/glycerin 3D porous scaffolds. Int. J. Biol. Macromol. 2018, 111, 158-168, https://doi.org/10.1016/j.ijbiomac.2017.12.136.

56. Lau, C. S.; Hassanbhai, A.; Wen, F.; Wang, D.; Chanchareonsook, N.; Goh, B. T.; Teoh, S. Evaluation of Decellularized Tilapia Skin as a Tissue Engineering Scaffold. Journal of Tissue Engineering and Regenerative Medicine. 2019, https://doi.org/10.1002/term.2928.

57. Zhang, W.; Zheng, J.; Tian, X.; Tang, Y.; Ding, G.; Yang, Z.; \& Jin, H. Pepsin-Soluble Collagen from the Skin of Lophius litulo: A Preliminary Study Evaluating Physicochemical, Antioxidant, and Wound Healing Properties. Marine Drugs 2019, 17, 708, https://doi.org/10.3390/md17120708.

58. Wang, J.; Xu, M.; Liang, R.; Zhao, M.; Zhang, Z.; Li, Y. Oral administration of marine collagen peptides prepared from chum salmon (Oncorhynchus keta) improves wound healing following cesarean section in rats. Food Nutr. Res. 2015, 59, 26411, https://dx.doi.org/10.3402\%2Ffnr.v59.26411.

59. Patra, J.K.; Das, G.; Fraceto, L.F.; Campos, E.V.R.; Rodriguez-Torres, M.D.P.; Acosta-Torres, L.S.; DiazTorres, L.A.; Grillo, R.; Swamy, M.K.; Sharma, S.; Habtemariam, S.; Shin, H.-S. Nano based drug delivery systems: Recent developments and future prospects. J. Nanobiotechnol. 2018, 16, 71, https://doi.org/10.1186/s12951-018-0392-8.

60. Guo, H.; Hong, Z.; Yi, R. Core-Shell Collagen Peptide Chelated Calcium/Calcium Alginate Nanoparticles from Fish Scales for Calcium Supplementation. J. Food Sci. 2015, 80, N1595-N1601, https://doi.org/10.1111/1750-3841.12912.

61. Veeruraj, A.; Arumugam, M.; Ajithkumar, T.; Balasubramanian,T. Isolation and characterization of drug delivering potential of type-I collagen from eel fish Evenchelys macrura. J. Mater. Sci. Mater. Med. 2012, 23, 1729-1738, https://doi.org/10.1007/s10856-012-4650-2.

62. Wang, W.; Itoh, S.; Aizawa, T.; Okawa, A.; Sakai, K.; Ohkuma, T.; Demura, M. Development of an injectable chitosan/marine collagen composite gel. Biomed. Mater. 2010, 5, 065009, https://doi.org/10.1088/17486041/5/6/065009.

63. Mei, F.; Liu, J.; Wu, J.; Duan, Z.; Chen, M.; Meng, K.; Chen, S.; Shen, X.; Xia, G.; Zhao, M. Collagen Peptides Isolated from Salmo salar and Tilapia nilotica Skin Accelerate Wound Healing by Altering Cutaneous Microbiome Colonization via Upregulated NOD2 and BD14. Journal of Agricultural and Food Chemistry 2020, 68, 1621-1633, https://doi.org/10.1021/acs.jafc.9b08002.

64. Wich Sangsuwan \& Pravit Asawanonda. Four-Weeks Daily Intake of Oral Collagen Hydrolysate Results in Improved Skin Elasticity, Especially in Sun-Exposed Areas: A randomized, double-blind, placebo-controlled trial. Journal of Dermatological Treatment 2020, https://doi.org/10.1080/09546634.2020.1725412.

65. Yang, F.; Qin, X.; Zhang, T.; Zhang, C.; \& Lin, H. Effect of Oral Administration of Active Peptides of Pinctada Martensii on the Repair of Skin Wounds. Marine Drugs 2019, 17, 697, https://doi.org/10.3390/md17120697.

66. Cruz, M. A.; Fernandes, K. R.; Parisi, J. R.; Vale, G. C. A.; Junior, S. R. A.; Freitas, F. R.; Renno, A. C. M. Marine collagen scaffolds and photobiomodulation on bone healing process in a model of calvaria defects. Journal of Bone and Mineral Metabolism 2020, 38, 639-647, https://doi.org/10.1007/s00774-020-01102-4.

67. Kavitha, N.; Karunya, T. P.; Kanchana, S.; Mohan, K.; Sivaramakrishnan, R.; Uthra, S.; Arumugam, M. Formulation of alginate-based hydrogel from brown seaweed, Turbinaria conoides for biomedical applications. Heliyon 2019, 5, e02916, https://doi.org/10.1016/j.heliyon.2019.e02916.

68. Cunniffe, G.M.; Brien, F.J.O. Collagen scaffolds for orthopedic regenerative medicine. The Journalof the Minerals, Met als and Materials Society 2011, 63 (4), 66-73, https://doi.org/10.1007/s11837-011-0061-y.

69. Sheehy; Lemoine; Clarke; Gonzalez; Vazquez; \& O’Brien. The Incorporation of Marine Coral Microparticles into Collagen-Based Scaffolds Promotes Osteogenesis of Human Mesenchymal Stromal Cells via Calcium Ion Signalling. Marine Drugs 2020, 18, 74, https://doi.org/10.3390/md18020074.

70. Liu, J.; Shibata, M.; Ma, Q.; Liu, F.; Lu, Q.; Shan, Q.; Bao, J. Characterization of fish collagen from blue shark skin and its application for chitosan- collagen composite coating to preserve red porgy (Pagrus major) meat. Journal of Food Biochemistry 2020, https://doi.org/10.1111/jfbc.13265.

71. Yang, F.; Jin, S.; \& Tang, Y. Marine Collagen Peptides Promote Cell Proliferation of NIH-3T3 Fibroblasts via NF-кB Signaling Pathway. Molecules 2019, 24, 4201, https://doi.org/10.3390/molecules24224201.

72. Chen, Y.; Jin, H.; Yang, F.; Jin, S.; Liu, C.; Zhang, L.; Tang, Y. Physicochemical, antioxidant properties of giant croaker (Nibea japonica) swim bladders collagen and wound healing evaluation. International Journal of Biological Macromolecules 2019, 138, 483-491, https://doi.org/10.1016/j.ijbiomac.2019.07.111.

73. Chang, W.J.; Shinichi, A.; Kamakura, S.; Huang, R.Y.; Chen, J.W. Bioengineering Materials in Dental Application. BioMed Res. Int 2017, 2017, 2135036, https://doi.org/10.1155/2017/2135036.

74. Tang, J.; Saito, T. Biocompatibility of Novel Type I Collagen Purified from Tilapia Fish Scale: An In Vitro Comparative Study. BioMed Res. Int 2015, 139476, https://doi.org/10.1155/2015/139476. 
75. Elango J.; Selvaganapathy, P.R.; Lazzarid, G.; Bao, B.; Wenhui, W. Biomimetic collagen-sodium alginatetitanium oxide $\left(\mathrm{TiO}_{2}\right)$ 3D matrix supports differentiated periodontal ligament fibroblasts growth for periodontal tissue regeneration, International Journal of Biological Macromolecules 2020, 163, 9-18, https://doi.org/10.1016/j.ijbiomac.2020.06.173.

76. Zhao, X.; Song, W.; Chen, Y.; Liu, S.; Ren, L. Collagen-based materials combined with micro RNA for repairing cornea wounds and inhibiting scar formation, Biomater. Sci. 2018, 7, 51-62, https://doi.org/10.1039/C8BM01054D.

77. Matica, M.A.; Aachmann, F.L.; Tøndervik, A.; Sletta, H.; Ostafe, V. Chitosan as a Wound Dressing Starting Material: Antimicrobial Properties and Mode of Action. International Journal of Molecular Sciences 2019, 20, 5889, https://doi.org/10.3390/ijms20235889. 